\title{
CHAPTER
}

\section{SELF-CARE AND TEAM CARE IN EMOTIONAL LABOR-INTENSIVE POSITIONS}

\section{Introduction}

Palliative care is challenging, yet rewarding work. The specialty falls beneath the umbrella of emotional labor-intensive positions. This means that in addition to job-specific responsibilities and duties, palliative care members are often in the position where they must fulfill role requirements while also managing and regulating their own emotions. While employees in most positions have to do this, palliative care is considered emotional labor because it revolves around providing comfort and care to those with serious and terminal illnesses. In this field, healthcare professionals are constantly exposed to others' emotional and physical suffering, which often leads to death and bereavement. Thus, even when team members lose a patient, they are expected to carry out duties throughout their shift. This requires special and intense emotional work to mask one's true emotions with emotions that are expected by peers and patients. This chapter discusses self-care and team care, and debunks misconceptions about working in emotionally intense positions. In the absence of self-care, palliative care professionals become even more susceptible to burnout and compassion fatigue.

\section{Negative Palliative Care Experience}

APRN Perspective: I went into this work because of my deep commitment to caring for people who are suffering. Lately, I never leave work on time, and I end up doing half of my charting at home. I feel like there will never be enough hours in the day, and I'm not serving anybody-my patients, my team, or my family. I used to look for chances to really engage with my patients, to find and address the sources of their

A podcast to accompany this chapter is available with online access of this title. Please see the instructions on the first page of the book for details on how to access and go to Chapter 7. 
suffering. Today, by the time I got to a patient's room, the family had already left. The nurse told me they are really struggling, but what I found myself thinking was "Thank goodness they already left so I can go chart." I don't even recognize myself anymore.

\section{Positive Palliative Care Experiences}

Chief Executive Officer Perspective: We signed up for this, and we know what it's [the dying process] like, but it's vital we don't take that for granted when interacting with those we serve.

Physician Perspective: You reach a point where psychologically you have to mark that space off for yourself, where you've got other activities that you do not neglect. Then you're not so immersed in this 24-7 that you lose sight of some of the other things that are happening. But you do have cases that are very touching and trying and that stick with you. You know? The ones that are as vivid now as they were 2 years ago. You have that, and it's just part of the nature of the work, too. I don't know what everybody else does for their own release for that, but I suspect that knowing how it [our team] has played out over time is each one of us probably does have pretty effective ways of coping and dealing with that emotional intensity in an ongoing way.

\section{Emotional Labor-Intensive Positions}

Palliative care typifies emotional work. Healthcare professionals use "their selves therapeutically to provide a healing presence to patients in life-threatening crises while simultaneously providing a means for healthcare professionals to cope when facing frequent losses" (Sans et al., 2015, p. 204). In other words, palliative care professionals and teams are instruments of healing but are, at the same time, vulnerable to emotional and pragmatic challenges associated with the profession (Mehta et al., 2016; Sanchez-Reilly et al., 2013).

In emotional labor-intensive positions, employees experience and demonstrate authentic emotional reactions as part of their occupational role (Miller, 2007). Healthcare professionals must then manage and regulate their emotions in normative ways that align with patient and organizational expectations. This means PCT members are expected to demonstrate authentic care and concern when engaging with patients and their families and while carrying out role responsibilities even when experiencing personal grief, such as in the case of losing a special patient. This can be particularly challenging when certain situations or patients look to you "to be a 'person' before a 'medical provider" (Omilion-Hodges \& Swords, 2016, p. 332), yet you are expected to put on a brave and professional front. 


\section{BOX 7.1}

\section{EXPLORING MEANINGFUL WORK}

Many in emotional labor-intensive positions describe their occupations as a calling or as meaningful work. They find a strong sense of purpose and meaning in their role.

In these cases, PCT members may answer the "who am I" question via their occupation. Their professional identity aligns so closely with their personal beliefs and values that they merge into a larger, shared identity.

Thus, one may not see themselves as a palliative care provider but rather identify as a caregiver at work, at home, and at leisure.

Some consider callings through a religious lens while others link meaningful work to passion. Regardless, scholars agree that a calling is an important psychological state that emphasizes skill variety, task identity, and significance.

\section{Benefits of Meaningful Work}

- Increased occupational skill

- More autonomy

- Increased job satisfaction

- Enhanced work-life balance

- Feeling as though one is utilizing one's personal skills/talents to the fullest

- Giving back to the community

Considering the personal responsibility and challenges associated with emotional labor-intensive positions, many tend to associate these positions with a calling or meaningful work that actively contributes to individual well-being (see Box 7.1). According to one palliative care physician, "these human interaction experiences that we can have, not only do they drain - they can-but we receive a lot from them, and we get energized by the work that we do and the potential impact that you have. And I think that, in a sense, insulates from some of [the harmful effects of emotional labor]."

In a routine shift, a palliative care provider will engage in a variety of discussions and situations that require emotional work. This work is likely to emerge 
in the following communicative situations (e.g., Considine \& Miller, 2010; Funk, Peters, \& Roger, 2017; Vedel et al., 2014):

- Helping patients and families to navigate confusion surrounding serious illness or end of life

- Discussing care options in the absence of curative treatment

- Providing patients with pain management strategies

- Mitigating family dynamics

- Engaging in conversations with patients and families about end-of-life, which may include religious, spiritual, or existential concerns

- Assisting patients and their families in treatment and care decisions

- Serving as the first line of bereavement when a patient dies

In addition to the emotion involved in the daily role responsibilities of palliative care, PCT members may experience emotional labor stemming from the personal grief that comes with caring for those with serious illnesses and at end of life (Funk et al., 2017). Thus, even though PCT members may feel as though they need to emote in specific ways (e.g., crying, yelling, taking a break), they are also expected to carry on as usual. This can help to exemplify why those "with an extra compassion bone" are often tagged for inclusion on PCTs and why Donald, a registered nurse in a pediatric palliative care unit, describes his ability to empathize as "his strongest trait and his kryptonite" (Omilion-Hodges \& Swords, 2016, p. 331).

\section{A Two-Pronged Approach to Emotional Labor}

Emotional labor is commonly considered in two distinct veins: job-focused and employee-focused.

Job-focused emotional labor: This aspect of emotional labor relates to the frequency, intensity, and expectations associated with the performance of emotions on the job. Applied to palliative care, this may entail approaching each patient and family interaction as if it were the first appointment of the day-where PCT members enter each encounter with their undivided attention and with energy (Box 7.2). This can be a tall order considering the length of provider shifts, the frequency of patient appointments, and the intensity of topics tackled during patient-provider interactions. Taken together, jobfocused emotional labor addresses interpersonal work demands, including the duration and frequency of interactions with patients and their families and emotion control, where PCT members are expected to emote in predictable 


\section{BOX 7.2}

\section{A NURSE REFLECTS: TREATING EACH PATIENT AS THE FIRST ONE OF THE DAY}

It was just one of those days. There were these five ladies who'd survived cancer together for over five years that I knew well, and one of them died. And I saw one of the other group members and cried with her over the death. And then I dried my tears and took a deep breath and went to see my next patient who l've also known for a long time, and she's not going to make it. And I cried outside her room, and then I dried my tears, took a deep breath, and went to see my next patient.

ways (i.e., in treating each patient encounter with the same degree of attention, concern, and sincerity).

Employee-focused emotional labor: Whereas job-focused emotional labor relates to occupational expectations, employee-focused emotional labor is specific to each individual team member. This aspect of emotional labor details how individuals process and make sense of managing their emotions to fulfill their professional responsibilities. In palliative care contexts, employee-focused emotional labor seeks to answer the following question: How do healthcare professionals regulate and/or modify their emotions as they work to fulfill patient and other role-related needs? The extent to which healthcare professionals find emotional labor debilitating varies. For example, when discussing work-life balance, APRN Kalista shared that:

"I have those issues anyway. I bring those with me. The work doesn't really affect that ...

Part of that comes from my style of wanting to make my supervisor look good. Those are internally driven neuroses of work-life balance issues and I've had those at every job. The good thing about this team is that everybody here will remind me when that gets out of balance."

Two distinct processes are part and parcel with employee-focused emotional labor: surface acting and deep acting. Though it sounds less onerous than deep acting, surface acting can lead to negative outcomes for providers. Surface acting involves PCT members modifying their outward expressions and behaviors to hide their authentic feelings. While this can be as minor as putting on a smile to conceal a bad mood, over time surface acting can lead to serious physical and psychological concerns. Additionally, surface acting has been linked to three dimensions of burnout: emotional exhaustion, depersonalization, 
and diminished accomplishment (Brotheridge \& Grandey, 2002). Kamal et al. (2016) found that of the $62 \%$ of palliative care professionals experiencing burnout, most stemmed from emotional exhaustion with depersonalization serving as a minor component.

PCTs can serve as a protective factor against surface acting. While professional practice may require situations of hiding authentic feelings, teams are a place where such feelings can be shared. Since team members spend so much time with one another, they are also good observers of the possible signs of burnout. Sharing feelings and experiences with the team also allows for another type of processing-humor. While many outside of healthcare do not see anything humorous in death or serious illness, all jobs have funny moments and occurrences. The important thing is using the right lens, when appropriate, to find the humor or lightness in even the most trying of situations (see Boxes 7.3A and 7.3B).

\section{BOX 7.3A}

\section{SOCIAL MEDIA AS SUPPORT: FINDING VALIDATION AND HUMOR IN TWEETS}

In addition to sharing stories in person, team members may post to social media or share posts that they see with one another. For example, the Twitter feed Palliative Dork shares stories about "Geeking out about anything and everything in palliative care" but also shows organizational tensions with tweets like:

"Is it inappropriate to type 'I told you so' in a progress note?" (May 29, 2019)

"Palliative: Have had extensive, daily goals of care discussions, family requests more time to consider $x 5$ days and counting. Geriatrics: Poor prognosis. Appreciate Palliative Medicine assistance-currently FULL CODE.-Yelling to get our attention? We KNOW." (April 5, 2019)

These social media posts display frustration that helps the palliative community feel connected and validated if they relate to the feelings. Another way to connect is through humor, and tweets often rely on humor that is specific to the field such as:

“Today I heard Miralax ${ }^{\circledR}$ mispronounced as Miracle-lax. I really don’t think it produces poop miraculously, but I will call it this from now on." (May 22, 2019)

SOURCE: Palliative Dork [@PCDorkClub]. Tweets: 5/29/19, 5/14/19, 4/5/19. Retrieved from https:// twitter.com/PCDorkClub 


\section{BOX 7.3B}

\section{HUMOR AT WORK: SOCIAL WORKER AND NURSE REFLECTIONS}

\section{A Social Worker Reflects}

We do a lot of inappropriate humor. I think it is typical hospital humor. A lot of humor about dying that people might think is irreverent. But we know the boundaries of it. I mean-it would never get said, obviously, outside of this conference room, or outside of 4 East. But I think you have to laugh. And one of the things that I appreciate about this group is their sense of humor. We get to laughing so hard that it's ridiculous. And it's a huge release.

\section{A Nurse Reflects}

I think it helps. Humor is certainly one of our ways that we help with coping. And it also creates some of the team camaraderie stuff that goes on, too. You know? It's okay that you can laugh at yourself. I think that also levels the playing field for us that we can laugh at ourselves and just realize "This was really crazy" or "I can't believe this just happened to me." Just sharing your story helps.

Deep acting is a more emotionally complex phenomenon. Unlike surface acting where PCT members occasionally fake emotions to meet role demands, deep acting describes the internal processes team members experience as they work through their emotions and make sense of their feelings and actions related to their role. This can help to reduce the discomfort associated with having to remain cheerful or brave in trying situations because PCT members who engage in deep acting will set aside time to address these feelings. Thus, while they may not be able to cry on the unit after losing a special patient, it is likely that they will take time on a break or after shift's end to lean into those feelings. Considering that it is the most emotionally healthy route, deep acting has also been linked to meaningful work. In palliative care, PCT members may enact specific emotions not only because they feel mandated by the organization to do so, but also because of their sincere belief that all patients are deserving of genuine interactions (Box 7.4).

While the education of palliative care professionals includes information and even warnings about the signs of burnout, it can be difficult to see while it is happening. The cumulative nature of the emotional wear and tear of the job can erode a PCT member's sense of normative reactions. Even healthcare professionals who 


\section{BOX 7.4}

\section{A PALLIATIVE CARE PHYSICIAN REFLECTS ON EMOTIONAL LABOR AND MEANINGFUL WORK}

Nurses and other human services workers report high levels of deep acting, which is related to a strong sense of personal fulfillment and a decrease in depersonalization (Brotheridge \& Grandey, 2002). This finding also helps to illustrate the link between palliative care and meaningful work.

Allan, a palliative care physician on a high-performing palliative care team, finds that the work itself helps him to deal with the emotional labor associated with the role:

"I think there are some things that offset the draining portion of it, and part of it is just that, recognizing that 'We made a difference in this particular situation. This could have gone really bad,' or 'This was heading down a path. ' And when you see that happening, even though it's very emotionally engaging, and you feel drained at times-you dothere is also this filling of the well again by your colleagues, as well as just the meaning of the work."

are more adept in general at deep acting and processing feelings associated with emotional work are not immune to compassion fatigue or burnout.

\section{Compassion Satisfaction and Compassion Fatigue}

Compassion is a core component of palliative care. In fact, many are drawn to palliative care and the field of medicine because of the joy that comes from helping others and the importance of working with patients and families as they experience serious illness.

\section{Compassion Satisfaction}

Compassion satisfaction stems from the positive feelings or validation that comes from being able to provide treatment (when applicable) and care to help alleviate pain and suffering in patients. In fact, compassion satisfaction is so integral to palliative care that it has been linked to (Sans et al., 2015): 
- Provider quality of life

- Provider self-awareness

- Increased ability to cope with death

- A decreased likelihood of burnout

Part of compassion satisfaction is practicing awareness and integrating selfcare practices into your daily routine. Practicing self-care individually and making it part of team practices can also help to prevent burnout, decrease team member conflict, guard against decreased empathy, and reduce absenteeism and turnover (Sans et al., 2015).

\section{Compassion Fatigue}

While compassion satisfaction is a contributor to higher work morale, compassion fatigue is the enemy of the helping professions. Compassion fatigue (Joinson, 1992) initially emerged in a study exploring burnout in emergency department nurses. In the face of extreme and continued tragedy, PCT members may lose their ability to form meaningful attachments with patients and to provide quality care. Recently, Cross (2019) further differentiated compassion fatigue from related concepts (e.g., burnout, secondary traumatic stress [STS], moral distress) in order to propose a definition specific to palliative care nursing. In this context, compassion fatigue is described as the condition that occurs when "compassion and empathy are lost, demonstrated by emotional and psychological, intellectual and professional, physical, social, and spiritual characteristics that, if left unattended, result in disinterest, moral distress, burnout, and breakdown" (Cross, 2019, p. 26).

Thus, compassion fatigue does not emerge solely from witnessing the pain and trauma of patients; it also emerges from heavy and/or expanding workloads, long shifts, or working within a culture that does not permit or promote opportunities for PCT members to talk about work-related stressors. PCT members are more vulnerable to compassion fatigue in certain circumstances including the following (Mooney et al., 2017; Sanchez-Reilly et al., 2013; Swetz, Harrington, Matsuyama, Shanafelt, \& Lyckholm, 2009):

- Being new or early within your career

- Untenable environmental issues such as unsustainable workload, poor management, and limited or no opportunities for professional or personal development

- Being female

- Working in an intensive care unit

- Feeling as though work-related circumstances are out of your control 
Attributing your successes to chance or external factors rather than reflecting on your own expertise and achievement

Teams that act more like a group of loosely connected individuals rather than as a true integrated interdisciplinary team may also contribute to provider compassion fatigue.

While considering these factors, it is important to remember that according to author Dr. Beth Hudnall Stamm, developer of the Professional Quality of Life (ProQOL) measure, "compassion fatigue is not a diagnosis. It is possible that compassion fatigue is a descriptive term and that a person struggling with compassion fatigue also has a psychological disorder" (https://proqol.org/CS _and_CF.html). For example, one PCT member may be experiencing compassion fatigue and also have a diagnosable level of depression. However, another PCT member may have compassion fatigue and not show signs of clinical depression.

While a number of different models of compassion fatigue exist, four components stand out as contributors to this phenomenon: burnout, secondary trauma, cumulative grief, and moral distress caused by feelings of helplessness (ProQOL; Sorenson, Bolick, Wright, \& Hamilton, 2016). When a combination of these factors outweighs the feelings of compassion satisfaction, compassion fatigue may occur. Research also indicates prevalent compassion fatigue among counselors, social workers, and physicians-all key players in PCTs. Compassion fatigue is related to the following outcomes in palliative care professionals (Sans et al., 2015):

- Increased likelihood of burnout

- Decreased ability to cope with death

- Decreases in self-awareness

Given the impact on individuals and teams, it is important to understand the elements and effects of compassion fatigue (Box 7.5 and Figure 7.1).

\section{Burnout}

Though the terms are not synonymous, compassion fatigue and burnout are often used interchangeably when discussing emotional labor positions. In the context of palliative care, burnout has been described as feelings of helplessness over one's work environment and the ability to make a difference (Cross, 2019). Burnout also tends to occur over a longer period of time (Sorenson et al., 2016). Further, Boyle (2011) pointed out that there are three distinguishing 


\section{BOX 7.5}

\section{COMPASSION FATIGUE IN PALLIATIVE CARE TEAM MEMBERS}

In addition to feeling as though they are unable to emotionally connect with patients and role responsibilities, team members experiencing compassion fatigue may also experience (Boyle, 2011):

- The inability to sleep or, conversely, the desire to stay in bed

- Headaches

- Moodiness

- Gastrointestinal distress

PCT members experiencing compassion fatigue report feeling ineffective at work because of a looming feeling of apathy or the inability to nurture others.

\section{Potential Lasting Effects}

If left untreated, compassion fatigue may permanently alter a provider's ability to enact compassionate care and finding meaning in role responsibilities (Boyle, 2011).

\section{Compassion Fatigue Is Progressive}

If PCT members do not take steps to seek professional help, find social support, and begin integrating self-care practices, they may not be able to return to experiencing the compassion satisfaction and the meaningful work they once knew.

factors between burnout and compassion fatigue: causes, timing, and outcomes (addressed in Exhibit 7.1).

\section{Burnout for Underresourced Palliative Care Staff}

While the differences between burnout and compassion fatigue are spelled out in Exhibit 7.1, it is important to note that palliative care members also have a high propensity for burnout. Over $50 \%$ of palliative care physicians are predicted to leave the practice by 2024 (Cavallo, 2014). Part of the reason that burnout is as prevalent as it is for palliative care providers is that patient demand often exceeds staffing (O'Connor, 2018). The perception of work as meaningful can be protective of burnout. However, as a study by Shanafelt et al. (2009) found, that protection has a limit. The researchers found that "those spending less than $20 \%$ of their time on the activity that is most meaningful to them had higher rates of burnout-53.8\% vs. $29.9 \% "$ (p. 990). 


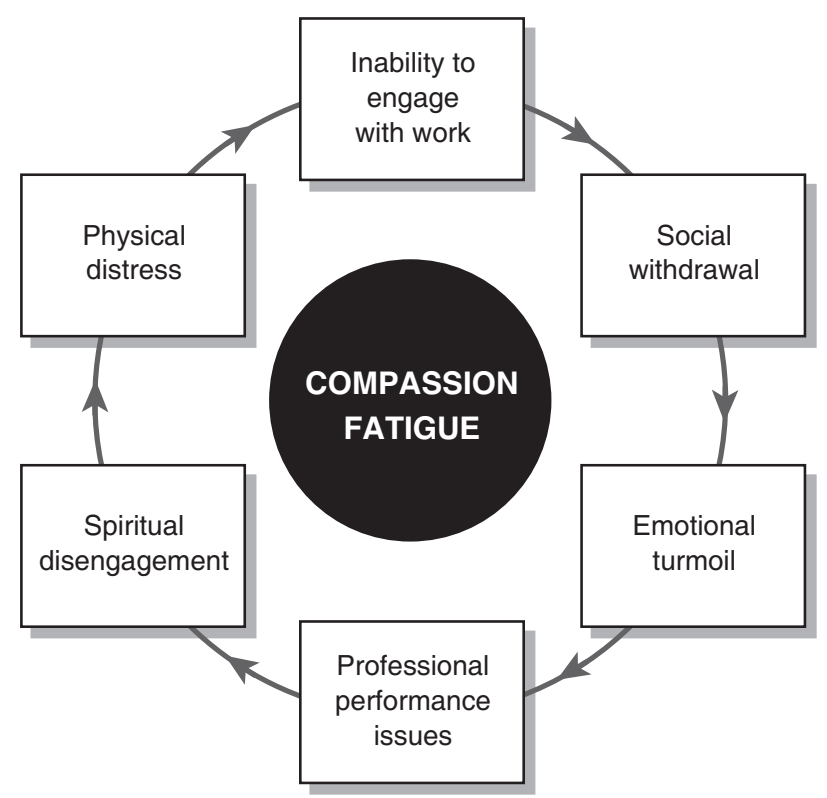

FIGURE 7.1 Outcomes of compassion fatigue.

\section{EXHIBIT 7.1}

\section{DISTINGUISHING BETWEEN COMPASSION FATIGUE AND BURNOUT}

\section{Causes: What may prompt burnout or compassion fatigue?}

Burnout-Linked to traditional organiza- Compassion fatigue-While burnout is tional stressors such as heavy workloads, linked to team member reactions to the limited or inadequate personnel, material, work environment, compassion fatigue or financial resources, and poor or trying is linked to the relational strain found in leader-member or peer relationships. emotional labor-intensive positions.

\section{Timing: When does burnout or compassion fatigue set in?}

Burnout-Because burnout is linked with Compassion fatigue - In contrast to burnenvironmental issues such as increased out, compassion fatigue tends to be emerworkload and/or deteriorating peer or gent. That is, after a particularly trying case, leader-member relationships, it tends to emerge slowly over time. clinicians may find themselves feeling as though they do not even recognize themselves, their feelings, or their behaviors. 


\section{Outcomes: How does burnout or compassion fatigue manifest or present in healthcare professionals?}

Burnout-Many times those who are Compassion fatigue-Those experiencexperiencing burnout transfer to different units or teams or different organizations. This is because the root of the discomfort is not related to the occupation, but rather the specific unit, team, or organization.

ing compassion fatigue will often try to bear the imbalance between administering treatment and the loss of empathy. If left untreated or if these feelings do not abate, healthcare providers may leave the occupation or attempt to start over in a new organization.

As palliative care professionals and teams are susceptible to burnout, creating and adhering to a team strategy for managing common work stressors may prove helpful. The PCT at the Hospital of the University of Pennsylvania serves as an excellent example. The team routinely found itself facing a daily census that exceeded the staff's ability to provide high-quality care. Instead of continuing to overstretch their limited resources, they strategized workflow practices for managing their growing consult demand (O'Connor, 2018):

1. Prioritize consults who are most likely to benefit from palliative care. That is, some consults may be better served by others (e.g., psychiatric social worker or pain management team) rather than the PCT.

2. Establish program-wide criteria to help decide which consults should continue with palliative care for the long term and which cases are able to be signed off on.

3. Determine if an interdisciplinary approach is required for the case-not every consult requires one. Members of this PCT consider the specifics of each case and determine if a social worker or a pharmacist, for example, may be better equipped than a physician or advanced practice provider (APP) to handle a consult.

4. Hold office hours with or regularly visit key referral sources to provide informational education and triage and streamline incoming consults.

5. Implement a cap. While this may not feel like an ideal solution, when consults vastly exceed staffing, it may be the only option. This approach should be discussed with organizational leadership and may serve to illustrate the need for additional resources. 
Being an underresourced PCT is stressful. Exhibit 7.2 highlights a conversation between team members where one member needs to vent and the other member assists her in remembering why she continues to do this work. Kelsey demonstrates active listening while also helping her colleague to reframe her situation. Since they have had this conversation many times before, Kelsey knows this is what Lillian needs right now-validation that her feelings of frustration are legitimate and a reminder that there are job perks here that she might not find elsewhere.

\section{EXHIBIT 7.2}

\section{TALKING THROUGH MOMENTS OF STRESS}

Whenever Lillian, an RN, has a tough day, she tends to have the following conversation with Kelsey, a social worker. While it is a repetitive conversation, it seems to be one that helps Lillian reframe her work and situation each time.

Lillian: I don't know why I even do this work! RNs aren't paid anything. I should just quit and do something else.

Kelsey: Well, you know you could. Although, it might be a hassle to look for a job.

Lillian: Yeah, it would.

Kelsey: But you might make more money somewhere else.

Lillian: I'd probably make a lot more.

Kelsey: Hmmm ... I wonder who you would work with?

Lillian: I wouldn't have the people I have here.

Kelsey: This is benefits versus burdens. No different than we do when we try to help our patients. Like, this location isn't convenient for me and I know I'm paid less than some other social workers. But this team, this team is a gift.

Lillian: Yeah, this team is a gift. 


\section{Secondary Traumatic Stress}

Working in palliative care can be stressful, even traumatic, at times. Providers who are personally involved in a traumatic event may experience primary traumatic stress. For example, a nurse who fractures a frail, elderly patient's ribs while performing CPR may experience this phenomenon. The feelings associated with primary traumatic stress may last for a long time even with appropriate coping techniques, a good support system, and possibly professional counseling.

While primary trauma is easier to identify as an occupational stressor, secondary traumatic stress, also known as vicarious trauma, is an underacknowledged factor in compassion fatigue (Sorenson et al., 2016). Given the nature of palliative care work, professionals in this field are closely involved with patients and families experiencing tragic or painful events. If secondary traumatic stress is not acknowledged and addressed, palliative care professionals' morale may begin to erode.

\section{Cumulative Grief}

Cumulative grief is another contributor to compassion fatigue (Carton \& Hupcey, 2014; Spilman, 2010). Constant exposure to sorrow, suffering, and death is a reality for PCT members. Additionally, PCT members are not necessarily afforded time to grieve for each patient before there is another loss. Spilman (2010) acknowledges that feelings of loss can be even greater if the members feel as though they were unable to provide a patient with a good death. Because cumulative grief is linked to compassion fatigue and burnout, research such as Carton and Hupcey (2014) reiterates the need to establish effective procedures that allow PCT members to adequately address the loss of their patients. For example, PCTs may use rituals (Box 7.6) to mark the deaths of patients and consider the meaning of their work as a part of those patients' and families' experiences.

\section{Moral Distress and Feelings of Helplessness}

Moral distress in palliative care may be the result of the inability to reconcile professional integrity with the clinical care situation. In other words, it is the feeling that something that is not good for the patient is happening anyway and the provider feels helpless to do anything about it. Palliative care professionals may experience moral distress as follows: 


\section{BOX 7.6}

\section{A CHAPLAIN REFLECTS: ACKNOWLEDGING THE DEATH OF PATIENTS THROUGH RITUAL}

Once a month, we use part of our weekly team meeting to acknowledge the passing of our patients. We have a basket of stones and a glass bowl. During the monthly ritual, we pick up a stone from the basket, say the patient's name, and place the stone into the bowl. As the stone is transferred, we might share something about the patient or our experiences with this person or family. No one is required to speak, and the stone might pass silently to the bowl-it's a space for people to speak up if they want to. After all of the names are spoken aloud, a chaplain offers a blessing. Every few months, once the basket is empty, we pass the bowl around from person to person. While we pass the bowl, we take a moment and appreciate the weight of the stones in the bowl. We think about how we experience that cumulative weight as palliative care professionals. Then we return the stones to the basket.

- Medical Futility: "Why would cardiology even offer that? They know it isn't going to help, and they just don't want to tell the patient."

- Injustice: "The system is broken! This medication would help the patient, but their insurance won't cover it. They expect the patient to pay out of pocket, and this person just can't."

- Colleagues' Choices: "That's not how to talk to this family. I know it isn't my job to tell a colleague how to act, but now the family doesn't trust us anymore. I don't think we have enough time left with this patient to rebuild that trust and help them like we do best."

All of the preceding examples involve feelings of helplessness on the part of the provider. When your vocation is patient care and the ability to best care for the patient is compromised by factors outside of your control, you may experience feelings of helplessness. These feelings may also be labeled as moral distress. PCT members will all likely experience feelings of helplessness throughout their careers due to the nature of the work (Back, Rushton, Kaszniak, \& Halifax, 2015; Cavallo, 2014).

Some have suggested using the feeling of helplessness as a barometer for gauging one's level of engagement with patients at any given time (Back et al., 2015). The researchers suggest that just as you would not expect a barometer to be static, it is not reasonable to expect that a PCT member's levels of empathy and engagement will be either. Illness progression can be unpredictable by nature, which, in 
turn, means that patients, their families, and PCT members may often feel like they are on an emotional rollercoaster. Back et al. (2015) suggest that this may lead members to experience a variety of sweeping emotions from apathy (hypoengagement) to anxiety and extreme vigilance (hyperengagement).

One way to address feelings of helplessness and the related challenges are to RENEW (Recognize, Embrace, Nourish, Embody, Weave). In their RENEW model, Back et al. (2015, p. 28) reiterate the importance for PCT members to (Figure 7.2):

1. Recognize: Take the time to recognize when feelings of helplessness are present

2. Embrace: Lean into their mental and physical feelings and address them (i.e., recognizing that you need time to process is not the same as taking time to process a case)

3. Nourish: Engage in nourishing or self-care behaviors that help them to feel restored

4. Embody: Enact engagement in terms of reconnecting with the challenging case or situation. This may include deep breathing or other mindfulness activities (refer to Boxes 7.10, 7.16, and 7.17 for examples specific to palliative care)

5. Weave: Select a new response that is both emotionally and cognitively healthy for them as caregivers

Box 7.7 highlights additional practical steps implemented by a high-performing PCT in order to continue to deliver exemplary patient-centered care while also helping to protect PCT members' well-being. 


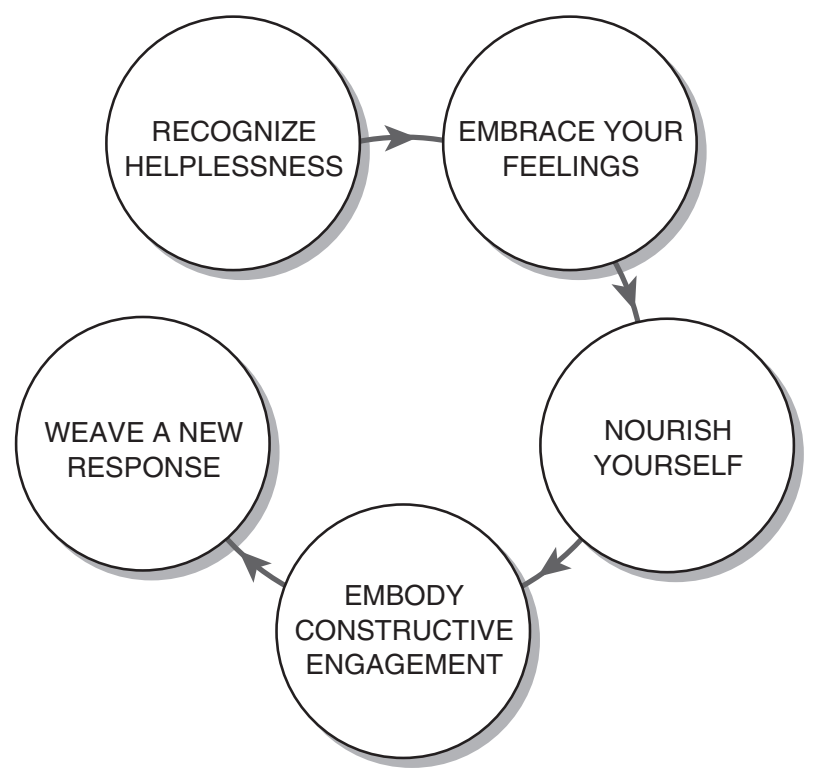

FIGURE 7.2 RENEW Model: Consider how to renew when feelings of helplessness present.

SOURCE: From Back, A. L., Rushton, C. H., Kaszniak, A. W., \& Halifax, J. S. (2015). "Why are we doing this?": Clinician helplessness in the face of suffering. Journal of Palliative Medicine, 18(1), 26-30. doi:10.1089/jpm.2014.0115

\section{BOX 7.7}

\section{PRACTICAL WORKFLOW STRATEGIES FOR OVERWORKED} PALLIATIVE CARE PROGRAMS

One high-performing palliative care team integrated the following practical strategies to manage their growing referral volume:

1. Hired and trained prn staff (social worker, chaplain, APRN) to work during high census periods and to cover other members when they are on leave or on vacation

2. Hired an additional APRN for both inpatient and outpatient service expansion

3. Developed intentional and consensus-based processes for signing off when no unmet specialty-level palliative care needs are identified

4. Developed a palliative care acuity system to facilitate appropriate "dosing" of palliative care professionals

5. Re-engaged team members in role delineation activities based on palliative care domains to ensure respect for professional roles and avoidance of task overlap 
6. Designed streamlined note templates to improve efficiency while maintaining excellent communication and documentation standards

7. Acquired new office space to accommodate new hires and allow for close interdisciplinary collaboration throughout the workday

8. Created primary palliative care training strategies for nonspecialty staff

9. Engaged available services from an administrative assistant to take on chart review/ data entry tasks from the RN coordinator

10. Developed a volunteer bereavement card coordinator position to relieve chaplains from an administrative task

11. Implemented team-building and self-care strategies to prevent burnout

Compassion fatigue and its components saddle healthcare professionals and interdisciplinary care teams with additional emotional burdens to bear and weather. Moreover, each requires immediate and sustained attention in addition to a re-evaluation of work-life balance and integration of self-care practices. As Faith, a director of palliative care, describes palliative care work: "It's messy, it's sad, it's a heartbreakingly real time for our patients. We can't appear, even for a moment, that we don't care, that we're not standing right there beside them" (Omilion-Hodges \& Swords, 2016, p. 332). There is a lot at stake-the care of the patient and family, as well as the ability of the provider to continue to do the job well and to be a functioning part of an interdisciplinary team. Therefore, paying attention to the causes of compassion fatigue and working to ensure a robust sense of compassion satisfaction are important.

It is one thing to notice the signs of compassion fatigue and another thing to do something about it at the team and/or organizational level. It would seem the simplest solution is encouraging team members to pass patients to another healthcare professional when compassion fatigue or its components are recognized. However, the use of this simple solution requires healthy teams who have a high degree of trust in one another and a willingness to encourage members to express when they are feeling overwhelmed. Team or organizational solutions 


\section{BOX 7.8}

\section{CALLING A CODE LAVENDER}

Code Lavender began as a crisis intervention tool at a Hawaiian hospital in 2004. A healthcare professional calling this code is signaling that he or she is having a rough time at work. When the code is called, the struggling team member receives a small packet of items. A study at the University of California San Diego teaching hospital distributed packets containing a lavender aromatherapy vial, a piece of chocolate, and a handwritten note with an encouraging quote. In this study, $100 \%$ of those receiving the packet found it to be helpful. While it did not change their Professional Quality of Life posttest scores, participants did report feeling that the organization recognized them and cared for them (Davidson et al., 2017).

such as Code Lavender (see Box 7.8) can be effective if the participants believe that letting others know they are feeling burnout will result in support. Mechanisms like this can be a boon to individual and team morale, but it is also important to note that team-care solutions such as passing off patients and Code Lavenders will not make up for underresourced teams over the long term. Finally, even in teams with great team-care practices, it is also important for individual PCT members to practice self-care.

\section{What Is Self-Care?}

Self-care is an essential component of personal and emotional well-being. Selfcare encompasses routine opportunities and integrated moments of care designed for balance, nourishment, and renewal. The Hospice and Palliative Medicine subspecialty identifies self-care as integral to provider well-being, satisfaction, and career longevity. In fact, the 2018 Annual Assembly of Hospice and Palliative Care held a town hall meeting dedicated to discussing the importance of clinician well-being and resilience by stressing the importance of self-care (Dahlin, Mastrojohn, \& Rotella, 2018).

It is important to note that self-care is not:

- A new-agey fad

- Indulgent 


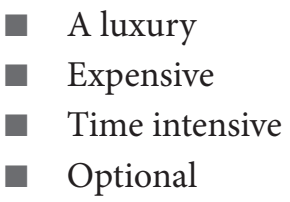

Self-care can be integrated into any schedule and any budget. Acts of self-care can help you to recharge and to maintain harmony between your occupational role and your personal roles (e.g., parent, spouse, friend, neighbor, community member; Box 7.9). Moreover, self-care is just as important for your physical health as it is for your mental well-being. Self-care also directly affects PCT members' quality of life. Compared with their peers who do not routinely engage in self-care, professionals who enact self-care practices enjoy a higher quality of life in addition to reporting higher levels of resilience and overall wellness (Ayala, Winseman, Johnsen, \& Mason, 2018; Melvin, 2015; Omilion-Hodges \& Swords, 2016; Sans et al., 2015).

\section{BOX 7.9}

\section{A PHYSICIAN REFLECTS: THE CRAP-TO-FUN RATIO}

When I've approached burnout, it's because I have not had enough time to have diversions. One of the things I came across when I was in college was the idea of rotating crops. Having things in your life that replenish you in different ways is helpful. I'm comfortable going from one activity to the next and trying to stay engaged realizing "Each one of these has different ways of replenishing you and filling your bucket." We have many dimensions to ourselves as human beings, and we have to touch all of those and try to build them into our life experience. Physically? I exercise. Spiritually? We go to church as a family, and I do daily practice for myself. Socially? As a physician, I'm in contact with people all the time and I really enjoy what I do. I also get to teach and sometimes play an administrative role. I tell people "You know, there's crap in our life and there's fun in our life. You have to manage the crap-to-fun ratio in your life. If there's too much crap, you have to go look for the fun, for the part you enjoy."

Recent research (Ayala, Omorodion, Nmecha, Winseman, \& Mason, 2017) identified clusters of self-care activities reported by medical students (see Box 7.10). 


\section{BOX 7.10}

\section{SELF-CARE ACTIVITIES FOR HEALTHCARE PROFESSIONALS}

Researchers (Ayala et al., 2017) identified 10 clusters of self-care activities as reported by medical students:

1. Nourishment: Eating healthfully, staying hydrated

2. Hygiene: Maintain physical health and appearance, getting adequate sleep, pampering (e.g., baths, long showers, manicures)

3. Intellectual and creative health: Follow current events; enjoy books and podcasts, and creative activities (knitting, choir, instruments, photography)

4. Physical activity: Regular exercise

5. Spiritual care: Attend religious services, pray, meditate, journal, reflection, therapy

6. Balance and relaxation: Designated downtime, boundaries, taking time off, breathing exercises

7. Time for loved ones: Dedicated time with romantic partners, family, and friends

8. Big picture goals: Consider 5- and 10-year plans

9. Pleasure and outside activities: Dinner out, time outdoors, cooking

10. Hobbies: Writing, reading for pleasure, arts and crafts, recreational sports

SOURCE: Ayala, E. E., Omorodion, A. M., Nmecha, D., Winseman, J. S., \& Mason, H. R. C. (2017). What do medical students do for self-care? A student-centered approach to well-being. Teaching and Learning in Medicine: An International Journal, 29(3), 237-246. doi:10.1080/10401334.2016 .1271334

\section{Benefits of Self-Care}

Self-care offers individuals a wealth of positive outcomes. In addition to being linked to increases in PCT members' quality of life, engaging in self-care practices can also result in the following benefits:

Work-Life Balance: While many palliative care professionals find meaning and fulfillment in their work, it does not mean the role should be all consuming. Integrating self-care allows PCT members to enjoy a balanced life where they find enjoyment in work and non-work-related activities (Box 7.9).

- Stress Management: Self-care is an effective means of addressing and alleviating stress. In addition to exercise, meditation, journaling, and prayer are commonly cited sources of stress abatement (Ayala et al., 2017). 
- Personal Worth: While many palliative care professionals identify as caregivers in and out of the clinical environment, they should practice turning those self-nurturing skills inward as well. The idea is reminiscent of the airline instructions to put on your mask before assisting others with theirs. In order to help patients, you must be healthy enough to be helpful. It is important to remember that neglecting self-care is not noble and is likely to result in feeling overwhelmed, stressed, and distracted in all facets of life including patient care.

- Physical Health: Without physical health, PCT members cannot care for their patients, their families, or themselves. Maintaining physical health can include engaging in regular physical activity, eating well, staying hydrated, and getting 7-9 hours of sleep as recommended by the National Sleep Foundation (2015). It is also important to make time for routine health checkups in addition to seeing experts for additional physical, mental, or emotional maintenance or concerns.

\section{Self-Care Is Essential}

In times of stress, such as high patient census or when teams are understaffed, PCT members' initial reaction may be to skip a break or put off lunch as a way to accomplish more work. They may cancel evening plans with friends or skip their regular Pilates class so that they can stay late to work on patient charts. Unfortunately, while this is a common practice, it is not a healthy one. Self-care is always important, but it becomes even more so as stress ramps up. Additionally, while cancelling plans and missing an occasional lunch break are not causes for concern if done rarely, these actions may have larger ramifications if done frequently. Most palliative care professionals know what would be a good self-care regimen but fail to follow through. As there is a link between commitment and consistency (Cialdini, 2009), taking the time to set goals and creating a plan to realize those goals increases the chance of follow-through.

\section{Balancing Your Needs in a Team Context}

Palliative care is hard but essential work. The impact of work-related stress on PCT members' well-being has long been documented (Berman, Campbell, Makin, \& Todd, 2007; Kearney, Weininger, Vachon, Harrison, \& Mount, 2009; Martins Pereira, Fonseca, \& Sofia Carvalho, 2011). PCTs (not just individual practitioners) are also susceptible to occupational stressors, which can lead to breakdowns in communication, provider withdrawal, and medical errors (Sanchez-Reilly et al., 2013; West et al., 2006). This prompts two natural questions: 
1. How do palliative care professionals balance their individual needs within the team context?

2. What can teams do to integrate self-care and team care into their daily roles and team processes?

The first question is explored in this section, and the chapter concludes with team-level suggestions for enhancing resiliency and decreasing stress while delivering intentional patient-centered care. While palliative care professionals can develop a solid foundation of wellness and resiliency through the personal selfcare activities (e.g., exercise, meditation, spending time with friends and family), there are also workplace-specific actions that can help to create a barrier against burnout and compassion fatigue.

In a thorough review of self-care activities related to palliative care professionals and oncologists, Sanchez-Reilly et al. (2013) suggest that providers engage in the following organizational activities:

- Developing and maintaining strong peer relationships

- Seeking out mentors

- Finding new ways to engage within the organization

- Reflecting regularly on workplace performance

- Improving management and communication skills

- Practicing mindfulness at work (Box 7.11)

\section{BOX 7.11}

\section{A CHAPLAIN REFLECTS: LEADING A BREATHING EXERCISE AT THE BEGINNING OF ROUNDS EACH MORNING}

I make them breathe every morning because it is important for us to just take the time and center ourselves - particularly for what we are dealing with. If I can just get them to inhale and exhale, it's good for each of us. When I first suggested it, they thought it was nice. But they thought it was just going to be that one time! And then the next day, they were ready to jump into patient care, and I said "Well, are we gonna breathe?" Some people are a little high strung and anxious some days, but l'm thinking "All I ask you for is 2 minutes of your time-2 minutes when I could ask you for 5 or 10." But I don't do that. And I wouldn't get it if I did. Now whoever is leading the meeting prompts me to start the breathing while also saying "And then we'll start on..." To me, that's acceptance versus "I hope she doesn't start with the breathing!" 
These suggestions largely align with the primary dimensions of self-care: physical, emotional, spiritual, financial, social, workplace, and future goal setting. Social integration, for example, gives PCT members sources of social support. Thus, rather than looking at the development of peer relationships as frivolous, recognizing the power of connecting with others who understand the unique highs and lows of palliative care is priceless and may offer the following benefits:

- Processing difficult emotions with others who have an intimate understanding of specific cases

- Having trusted confidants in the workplace (which may develop into lasting friendships)

- Access to work-related advice (e.g., pain or symptom management, how to deal with the team leader)

- Access to job-related affirmation for your skills and decision-making

- A barrier against isolation

Many suggestions (Sanchez-Reilly et al., 2013) for individual self-care within organizational settings align with the emotional and professional health and future goal-setting dimensions of self-care.

- Self-care is not only about nourishing yourself now; it is also considering what steps or factors will allow you to continue to grow personally and professionally. Seeking mentors and finding new ways to engage at work are clear paths for doing so.

- Taking time to reflect on work performance can enhance your emotional and professional health. This allows you to consider areas for improvement, additional skills, or training you would like to hone or acquire and consider how you see yourself developing as your career progresses. This reflection is also helpful in allowing palliative care professionals to consider if they have an interest in becoming a team leader or member of management in the future or if they would find more fulfillment in continued patient work.

- Practicing mindfulness in the workplace comes with a slew of benefits from increased patient-centered care, provider self-care and well-being, and development of enhanced empathy (Beckman et al., 2012; Kabat-Zinn, 2006; Mehta et al., 2016).

- Embracing empathy is another recommended way for palliative care professionals to deal with work-related stress (Harrison \& Westwood, 2009; Kearney et al., 2009). 


\section{Protecting Oneself Through Empathy and Boundary Setting}

A common misconception of displaying empathy, or engaging with and sharing feelings with another, is that it always depletes or takes away from a caregiver's personal well-being. However, Harrison and Westwood (2009) found that peer-nominated master therapists, including those in palliative care, used exquisite empathy to protect themselves from burnout and emotional depletion in addition to using traditional self-care measures such as seeking social support, practicing mindfulness, setting and maintaining boundaries (Box 7.12), and professional satisfaction and meaning.

\section{BOX 7.12}

\section{UNINTENDED CONSEQUENCES OF SKIPPING LUNCH AND STAYING LATE}

While it may feel like the only way to stay afloat is to skip breaks or to cancel plans to catch up, these actions come with unintended consequences. If you or one of your colleagues routinely engages in these behaviors, consider the associated outcomes and personal costs before doing so.

- You will not change the organization: If your team is still able to care for patients and administrative needs are met, senior leadership may not be able to see the extent to which more resources are needed.

- You give your consent: You tacitly okay this level of work and working conditions by consistently working through breaks or staying late or coming in early.

- You damage relationships: Loved ones understand when you have to cancel occasionally - especially if it means that you take time to recharge your batteries and engage in self-care. However, if you repeatedly prioritize work over them, relationships may become strained.

- You deprive your physical and emotional well-being: It is incredibly challenging to care for others if you are not properly caring for or addressing your own physical, emotional, and relational needs.

- You are too tired to provide exemplary care: Sustained periods of stress including being understaffed, overworked, or picking up extra shifts can leave you unable to be the care provider you strive to be. 
Exquisite empathy involves clarity about personal and interpersonal boundaries so that as PCT members develop meaningful connections with patients, they are also able to protect themselves from absorbing or taking on vicarious trauma (Harrison \& Westwood, 2009). In this sense, connecting with the intent to create a collaborative, genuine alliance can actually contribute to PCT members' health through the meaning they find in the work. Put simply, leaning into natural feelings of compassion and embracing connections with patients may be more beneficial to PCT members than working to create distance or maintain very strict or rigid boundaries (Box 7.13).

\section{BOX 7.13}

\section{PALLIATIVE CARE TEAM MEMBERS REFLECT ON THE NOURISHING POWER OF EMPATHY}

John, a palliative care clinician in a faith-based health system: "I feel much closer to my patients and fuller as a person when they express their frustration, disappointment or fear and I'm able to look them in the eye and tell them 'I'm scared too' or 'I'm sad too.' They know that l'm there with them and l'm honoring myself, too, instead of pretending it's all okay or business as usual” (Omilion-Hodges \& Swords, 2016, p. 332).

Warun, another palliative care physician from a high-performing team, also considers how empathetic encounters can enhance or contribute to provider well-being by reiterating the meaning of the work, saying:

"When you have some positive experiences-everybody's maybe a little bit different, but for me, one of the things that probably helps me through some of this is when you realize you've made a connection with the family and the patient, and you see the transformation occur during your encounter. You see that maybe you've been able to help with a catharsis, and you get people emoting better, and it's out there on the table, and you see that they're relieved at the end. You realize, 'That was good; that helped; that was an important piece.'”

\section{How to Build Continual Self-Care and Team-Care Into Effective Teams}

Just as PCT members are vulnerable to burnout, so are the teams themselves. This is especially true if environmental issues in the workplace, such as an unsustainable workload or poor management, continue to hamper a PCT's ability to focus on patient care. 
This section builds on the previous with best practices and ideas that PCTs can integrate into their daily practices to protect themselves from some of the challenges of their occupation. Team leaders, in particular, may find these ideas helpful for facilitating a healthy work environment for team members by focusing on skills-based interventions that build resiliency (Back, Steinhauser, Kamal, \& Jackson, 2016).

Figure 7.3 illustrates the most common factors that can contribute to a PCT's collective functioning through the development of strong leader and peer relationships, a sustainable workplace, and environment that is conducive to and rewarding of exemplary patient care.

1. Environmental Factors: High-stress and emotional labor-intensive work environments such as palliative care programs can be breeding grounds for burnout if not thoughtfully designed and run. Environmental factors, such as adequate work space, equipment, and staffing, can either help to foster a healthy environment that is conducive to patient-centered care or one that overburdens PCT members so that they are not able to focus primarily on

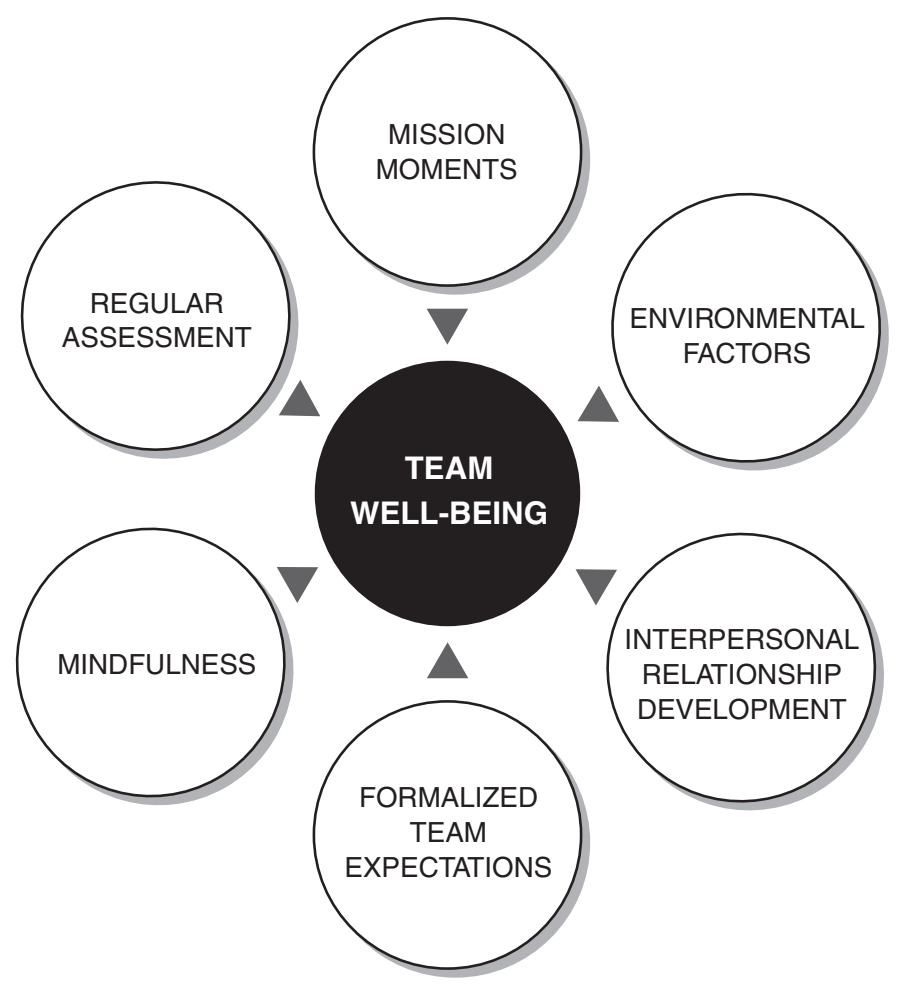

FIGURE 7.3 Factors that enhance team well-being and collective functioning. 
patient needs. The importance of team leadership to mitigate these factors was discussed in Chapter 4, Leading Palliative Care Teams.

2. Interpersonal Relationship Development: One of the major strengths of palliative care-delivered via interdisciplinary teams-can also be a weakness if not approached thoughtfully. Members should be trained and spend time discussing individual and group roles. Team leaders can remind members of role flexing (Dahlin, Coyne, Goldberg, \& Vaughan, 2019; Nancarrow et al., 2013) and blurring (Sims, Hewitt, \& Harris, 2015) so that all members approach care from a perspective of "we" rather than "I." Studies recommend PCTs undergo training on group communication as a means to foster a supportive work community (Sanchez-Reilly et al., 2013; Shanafelt et al., 2005; Swetz et al., 2009). Similarly, team leaders should carve out time for members to enjoy some time socially together. This could be in the form of bringing in coffee and bagels before a meeting or catering a team lunch or another way for team members to spend some informal time together. Far from being seen as idle chatter, research shows that when team members get to know each other as people they are more likely to develop supportive, trusting two-way relationships (Omilion-Hodges \& Ackerman, 2018). This is particularly important in the palliative care environment where members need to trust each other to augment and occasionally fill their own roles (see the example in Box 7.14).

\section{BOX 7.14}

\section{SUPPORTIVE TEAM RELATIONSHIPS IN PALLIATIVE CARE}

Johnny, a social worker in a palliative care program, shared an example of the importance peers can play in managing the emotions associated with palliative care. When he was the only social worker left on the team at 4:00 p.m. on Friday, Hadley, a palliative care clinical nurse specialist, came in and said "What can I do? I know you've had a rough day, and how can I help?" In addition to offering him assistance, Hadley also came bearing chocolate. While it was a minor gesture and one that may be seen as tangential to Hadley's own nursing responsibilities, Johnny reiterated how much the support meant: "... when we get distressed about a case, or upset, there's a lot of immediate support." This immediate support can help to assuage the negative effects of surface acting.

3. Formalized Team Expectations: Formalized team expectations largely stem from the team leader's explicit instructions and behaviors. A team leader, for example, may assign or encourage mentorship or work buddies. The former is often considered to be a more formal arrangement, where the mentor and mentee have regularly scheduled meetings, set collaborative 
goals, and consider professional and personal indicators of success (Disch, 2018). The latter, while less formal, can pair professionals to create a firstline source of informational support in the form of job-related duties and of social support during especially trying days. Relatedly, team leaders should also articulate and uphold clear guidelines for addressing conflict and miscommunication among members (Box 7.15).

\section{BOX 7.15}

\section{ACHIEVING A BETTER WORK DAY THROUGH FLEXIBILITY}

One high-performing palliative care team noticed that, despite their best efforts to divvy up work evenly among PCT members in the morning, individual team members' responsibilities might take more or less time than expected. One PCT member might end up with a number of time-consuming events such as an unplanned family meeting, a patient death, or a new, complicated referral whereas another PCT member's day goes smoothly.

Rather than just sticking with the original plan for the day, which would leave the first PCT member to work late, a PCT leader suggested sending out a group text to the team at 2:30 p.m. to see who had capacity to take on some tasks to even out the work load a bit. They tried it for a week to evaluate its effect. Once they tweaked the intervention (changed the time to 3:00 p.m. and reassigned texting responsibility to the RN), they found that team members felt better supported and were more likely to leave work on time so they continued the practice.

For example, a team leader may notice an increase in chatter about an unsatisfactory interaction with a PCT member that does not include that person in the conversation. While venting can be healthy, this kind of talking about rather than with someone is not healthy for the team. Talking with the team member will also illuminate if the issue is a misunderstanding or a true conflict of interest or value. It is important that team leaders acknowledge that misunderstandings happen and often emerge because PCT members are steadfast in their commitment to patient care. In turn, team leaders must also formalize the steps that members, including the team leader, are expected to take if they need to resolve an issue or air a complaint with a peer.

4. Mindfulness: Aside from environmental factors, making PCT members aware of mindfulness and making space for the practice is likely the most impactful team factor for team and member wellness and well-being. Mindfulness is the state of remaining present and focused in the moment. Such attentiveness is linked with adaptive, genuine, and reflective communication 
(Burgoon, Berger, \& Waldron, 2000). Practicing mindfulness and mindful communication in the healthcare environment has been linked to increased patient safety and delegation (Anthony \& Vidal, 2010), provider and team wellness (Beckman et al., 2012; Mehta et al., 2016), and the ability to develop authentic relationships with patients (Omilion-Hodges \& Swords, 2016).

An additional benefit of mindfulness is the many paths that lead to it (Box 7.16). For example, some PCTs have undergone stress reduction and mindfulness sessions collaboratively in order to build collective resiliency (Mehta et al., 2016), whereas individual practitioners may find that journaling, blogging, praying, or meditating will also help them to learn how to remain in the present (Kearney et al., 2009; Omilion-Hodges \& Swords, 2016).

\section{BOX 7.16}

\section{PREPARING FOR WORK, TACKLING THE DAY, AND LEAVING WORK AT WORK}

Palliative care professionals have found that establishing routines for getting into the mind-set of work, remaining present at work, and preparing to transition home have been helpful. Here are some practices that you may also find helpful (drawn from Omilion-Hodges \& Swords, 2016, p. 332).

\section{Before work}

- Reflect on a personal care mantra (e.g., "I serve body, mind, and spirit").

\section{At work}

- Using a pin, necklace, or other accessory as a reminder to stay present. One palliative care clinician wears a religious pin on her lab coat and touches it to remember to stay "in the present and attend fully to the patient."

\section{After work}

- Journal or blog to reflect on the day before leaving for home in order to "reflect on the sanctity of my job" and "to process the emotions of the day."

\section{Anytime}

- Mediation, prayer, and/or deep breathing to stay in the moment and practice mindfulness as a means to "remind us why we do this [palliative care]."

SOURCE: Omilion-Hodges, L. M., \& Swords, N. M. (2016). Communication that heals: Mindful communication practices from palliative care leaders. Health Communication, 31(3), 328-335. doi:10.1080/10410236.2014.953739 
5. Regular Assessment: Regular assessment allows the team leader and members to check in with their professional progress. This team-based factor involves having clearly defined processes and opportunities for professional development whether through continued medical education courses or by setting a tentative promotion plan with the team leader. Regular assessment also rests on honoring PCT members' autonomy to use their expertise as they see fit and rewarding those who continually demonstrate excellence in team-based patient-centered care (Balch \& Copeland, 2007).

6. Mission Moments: In many ways, palliative care is mission work. That is, the focus of palliative care aligns with many healthcare centers' mission of providing holistic care. One clear way to boost and maintain team morale is to highlight the meaning of the work that is carried out by PCTs (Mehta et al., 2016). Team leaders may connect with their organization's marketing team to learn how to highlight members' contributions, and less formally, team leaders may consider awarding a weekly or monthly mission moment member by praising specific instances of exemplary care (Sanchez-Reilly et al., 2013). As Gus, a palliative care physician, explains, "I think the other piece that's part of it is that everybody generally enjoys their work, and that helps a lot. This is not drudgery at all." This aligns with suggestions (Harrison \& Westwood, 2009) that drawing meaning from emotional labor-intensive positions and encouraging satisfaction in professional endeavors may help to protect members from burnout.

\section{Keys to Integrating Self-Care Practices Into the Team Environment}

Drawing from a successful PCT-based intervention designed to increase resiliency and decrease stress (Back et al., 2016; Mehta et al., 2016), three factors are likely to help facilitate self-care practices within the workplace.

1. Palliative Care Professionals Must Be Involved From the Start: Successful programs should be developed by or at least in concert with palliative care leaders and team members. Since they will ultimately be the end users of the practices or the self-care program, it is important that palliative care professionals are able to express needs and provide feedback in order to design interventions that directly apply to the work they do.

2. Needs and Outcomes Should Be Clearly Identified: In order for a new program or process to work, a clear need or gap must first be identified. PCTs may designate meeting time to prioritize self-care needs or 
environmental issues that can be addressed that will decrease the collective stress of the program.

3. Take a Skills-Based Approach: By creating interventions or processes that teach palliative care professionals new skills, such as conflict management, interpersonal relationship development, or mindfulness, they may incorporate this knowledge into all aspects of their lives. Beyond employing newly learned mindfulness (see Box 7.17 for mindfulness suggestions related to the delivery of palliative care) in the workplace, PCT members will also benefit by using these skills in their personal life. Bottom line: A skillsbased approach may help to increase provider self-care and well-being in and out of the workplace.

\section{BOX 7.17}

\section{INTEGRATING MINDFUL COMMUNICATION IN PALLIATIVE CARE}

Mindfulness describes a state where individuals stay focused and attuned to the present moment. While this sounds easy enough, consider how often you mentally return to your to-do list, consider what to make for dinner, and revisit that disagreement you had with your partner the night before. Following are some mindful communication practices shared by palliative care physicians.

\section{Key Practice: Consider your audience(s).}

In the day in and day out practice of palliative care, it can be easy to forget the magnitude of your role. As one palliative care clinician acknowledged: "When I first started out, I thought I knew best. l'd walk up to a patient, l'd already reviewed their chart, and I thought I knew them. I went on like this until my mentor told me, 'It's not about you. It's about them. You never even considered how they feel. ... Just be there with them.' It was humbling and at the time, humiliating and infuriating, but the single most important piece of advice l've ever received. It's also the first lesson I teach new residents" (Omilion-Hodges \& Swords, 2016, pp. 331).

\section{Key Practice: Ask questions. Listen. Repeat.}

Bill, a physician and medical director of a palliative care unit, stresses the importance of authenticity in patient-provider relationships. In fact, he refers to authenticity as a "relational slingshot" because it leads to "mutual and trusting relationships" and rapport development with patients (p. 331). Relatedly, Linda, a palliative care physician, suggests that she "scrutinizes" her early encounters with new patients so that she can tailor her communication, because they "walk this path together." The point of this key practice is to be fully present in patient encounters and not be perceived 
as just going through the motions of standard procedures. In Bill's advice to new residents: "be authentic even if they [new residents] are authentically awkward or shy or quiet. Whatever it is, as long as it is them and they are fully present in the conversation" (p. 331).

\section{Key Practice: Discard scripts.}

"We encourage our physicians to run to conflict, not away from it. We even provide bad death stories so they can learn. But we never provide a script. Even if it's not perfect, people can tell they're trying," stated Jim a palliative care physician (pp. 331-332). While scripts may be a helpful educational tool to provide students and residents with the scaffolding for challenging conversations, palliative care professionals should never be perceived as delivering a memorized cookie-cutter speech.

\section{Key Practice: Recognize your role.}

The final key mindful communication practice combines the three previous strategies. Lynn, a medical director of a palliative care unit, helped to illuminate this idea by reminding PCT members: "Whether you like it or not, or whether you're conscious of it or not, you're part of their [the patient and their family's] story" (p. 332). Remaining mindful and present with each patient can help you remember that while it is a normal Tuesday for you, it is likely a life-changing day for your patients and their family members. Lynn suggested that as PCT members complete their role-related duties that they remember that they're "a main character" in their patients' stories (p. 332).

SOURCE: American Hospital Association. (2019). Circle of life criteria. Retrieved from http://www.aha .org/about/awards/col/criteria.shtml; Omilion-Hodges, L. M., \& Swords, N. M. (2016). Communication that heals: Mindful communication practices from palliative care leaders. Health Communication, 31(3), 328-335. doi:10.1080/10410236.2014.953739

\section{PEARLS FROM THE FIELD: PROVIDER AND TEAM TAKEAWAYS}

Palliative care professionals who practice self-care report a higher quality of life than peers who do not make self-care a priority. In addition to being more content in life, those who practice self-care are taking proactive measures to guard against the harmful effects of compassion fatigue and burnout.

Takeaway 1: Palliative care is challenging, emotionally intensive work.

Palliative care requires PCT members to comfort, support, and care for those with terminal, serious, and chronic illnesses day in and day out. In addition to 
these job-related charges, palliative care professionals are called to be adept communicators and relationship builders, often forging deep and meaningful connections with their patients and their patients' families. These meaningful relationships with patients can be both a sustaining and a draining part of being a palliative provider. Consistently witnessing the suffering and grief of others is challenging, and it becomes even more challenging when PCT members are expected to act in normative ways—remaining professional—when they are hurting or dealing with loss. Considering that getting to know, caring for, and going through the highs and lows of illness with patients is the cycle of palliative care, it is essential that PCT members develop healthy coping mechanisms, such as routine self-care measures, to bolster compassion satisfaction and to guard against burnout and compassion fatigue.

\section{Takeaway 2: Self-care is an individual and team priority.}

Palliative care professionals are responsible for integrating self-care into their personal and professional lives. As noted earlier, self-care has been identified as an essential practice for provider well-being by the Hospice and Palliative Medicine subspecialty. Through self-reflection, consideration of the dimensions of self-care, and creating a personalized self-care plan, PCT members can help to shield themselves from some of the challenges associated with the profession. However, this should not fall solely on individual PCT members (A self-care plan template is available at www.springerpub.com/palliativecareteam and at connect.springerpub.com/content/book/978-0-5806-2/ch07.). Team leaders should also consider meaningful ways of integrating self-care into the workplace and by cultivating a supportive team environment. Whether it is by shielding members from challenging work conditions, advocating for adequate resources, holding regular trainings related to personal (i.e., communication training) and professional (i.e., team stress reduction) development, or assigning work buddies or mentors, team leaders are in an influential position to help to create a workplace that allows members to focus on care delivery and not common organizational headaches.

\section{References}

American Hospital Association. (2019). Circle of life criteria. Retrieved from http://www .aha.org/about/awards/col/criteria.shtml

Anthony, M. K., \& Vidal, K. (2010). Mindful communication: A novel approach to improving delegation and increasing patient safety. OJIN: The Online Journal of Issues in Nursing, 15(2). doi:10.3912/OJIN.Vol15No2Man02 
Ayala, E. E., Omorodion, A. M., Nmecha, D., Winseman, J. S., \& Mason, H. R. C. (2017). What do medical students do for self-care? A student-centered approach to well-being. Teaching and Learning in Medicine: An International Journal, 29(3), 237-246. doi:10.10 80/10401334.2016.1271334

Ayala, E. E., Winseman, J. S., Johnsen, R. D., \& Mason, H. R. C. (2018). U.S. medical students who engage in self-care report less stress and higher quality of life. BMC Medical Education, 18(1), 189. doi:10.1186/s12909-018-1296-x

Back, A. L., Rushton, C. H., Kaszniak, A. W., \& Halifax, J. S. (2015). "Why are we doing this?": Clinician helplessness in the face of suffering. Journal of Palliative Medicine, 18(1), 26-30. doi:10.1089/jpm.2014.0115

Back, A. L., Steinhauser, K. E., Kamal, A. H., \& Jackson, V. A. (2016). Building resilience for palliative care clinicians: An approach to burnout prevention based on individual skills and workplace factors. Journal of Pain and Symptom Management, 52, 284-291. doi:10.1016/j.jpainsymman.2016.02.002

Balch, C. M., \& Copeland, E. (2007). Stress and burnout among surgical oncologists: A call for personal wellness and a supportive workplace environment. Annals of Surgical Oncology, 14(11), 3029-3032. doi:10.1245/s10434-007-9588-0

Beckman, H. B., Wendland, M., Mooney, C., Krasner, M. S., Quill, T. E., Suchman, A. L., \& Epstein, R. M. (2012). The impact of a program in mindful communication on primary care physicians. Academic Medicine, 87, 815-819. doi:10.1097/ACM.0b013e318253d3b2

Berman, R., Campbell, M., Makin, W., \& Todd, C. (2007). Occupational stress in palliative medicine, medical oncology and clinical oncology specialist registrars. Clinical Medicine, 7, 235-242. doi:10.7861/clinmedicine.7-3-235

Boyle, D. A. (2011). Countering compassion fatigue: A requisite nursing agenda. The Online Journal of Issues in Nursing, 16(1), 1-13. doi:10.3912/OJIN.Vol16No01Man02

Brotheridge, C. M., \& Grandey, A. A. (2002). Emotional labor and burnout: Comparing two perspectives of "people work". Journal of Vocational Behavior, 60, 17-39. doi:10.1006/ jvbe.2001.1815

Burgoon, J. K., Berger, C. R., \& Waldron, V. R. (2000). Mindfulness and interpersonal communication. Journal of Social Issues, 56(1), 105-127. doi:10.1111/0022-4537.00154

Carton, E. R., \& Hupcey, J. E. (2014). The forgotten mourners: Addressing health care provider grief-A systematic review. Journal of Hospice \& Palliative Nursing, 16(5), 291-303.

Cavallo, J. (2014). Survey finds high rates of burnout among palliative care physicians, with over $50 \%$ predicted to leave the field in 10 years. Retrieved from https://www.ascopost .com/News/19602

Cialdini, R. B. (2009). Influence: Science and practice (Vol. 4). Boston: Pearson Education.

Considine, J., \& Miller, K. (2010). The dialectics of care: Communicative choices at the end of life. Health Communication, 25, 165-174. doi:10.1080/10410230903544951

Cross, L. A. (2019). Compassion fatigue in palliative care nursing: A concept analysis. Journal of Hospice and Palliative Nursing, 21(1), 21-28. doi:10.1097/NJH.0000000000000477

Dahlin, C., Coyne, P., Goldberg, J., \& Vaughan, L. (2019). Palliative care leadership. Journal of Palliative Care, 34, 21-28. doi:10.1177/0825859718791427

Dahlin, C., Mastrojohn, J., \& Rotella, J. (2018, March). Critical conversations: Challenges to clinician well-being and resilience in hospice and palliative care. In I. C. Fineberg (Moderator), Town hall with AAHPM, HPNA, and NHPCO. Symposium conducted at the Annual Assembly of Hospice and Palliative Care, Boston, MA.

Davidson, J. E., Graham, P., Montross-Tomas, L., Norcross, W., \& Zerbi, G. (2017). Code lavender: Cultivating intentional acts of kindness in response to stressful work situations. Explore, 13(3), 181-185. doi:10.1016./j.explore.2017.02.005 
Disch, J. (2018). Rethinking mentoring. Critical Care Medicine, 46(3), 437-441. doi:10.1097/CCM.0000000000002914

Funk, L. M., Peters, S., \& Roger, K. S. (2017). The emotional labor of personal grief in palliative care: Balancing caring and professional identities. Qualitative Health Research, 72(14), 2211-2221. doi:10.1177/1049732317729139

Harrison, R. L., \& Westwood, M. J. (2009). Preventing vicarious traumatization of mental health therapists: Identifying protective practices. Psychotherapy: Theory, Research, Practice, Training, 46(2), 203-219. doi:10.1037/a0016081

Joinson, C. (1992). Coping with compassion fatigue. Nursing, 22(4), 116-118.

Kabat-Zinn, J. (2006). Mindfulness-based interventions in context: Past, present, and future. Clinical Psychology: Science and Practice, 10(2), 144-156. doi:10.1093/clipsy.bpg016

Kamal, A. H., Bull, J. H., Wolf, M. S., Swetz, K. M., Shanafelt, T. D., Ast, K., ... Abernathty, A. P. (2016). Prevalence and predictors of burnout among hospice and palliate care clinicians in the U.S. Journal of Pain and Symptom Management, 51(4), 690-696. doi:10.1016/j.jpainsymman.2015.10.020

Kearney, M. K., Weininger, R. B., Vachon, M. L., Harrison, R. L., \& Mount, B. M. (2009). Self-care of physicians caring for patients at the end of life: "Being connected... a key to my survival." The Journal of the American Medical Association, 301(11), 1155-1164. doi:10.1001/jama.2009.352

Martins Pereira, S., Fonseca, A. M., \& Sofia Carvalho, A. (2011). Burnout in palliative care: A systematic review. Nursing Ethics, 18(3), 317-326. doi:10.1177/0969733011398092

Mehta, D. H., Perez, G. K., Traeger, L., Park, E. R., Goldman, R. E., Haime, V., ... Jackson, V. A. (2016). Building resiliency in a palliative care team: A pilot study. Journal of Pain and Symptom Management, 51, 604-608. doi:10.1016/j.jpainsymman.2015.10.013

Melvin, C. S. (2015). Historical review in understanding burnout, professional compassion fatigue, and secondary traumatic stress disorder from a hospice and palliative nursing perspective. Journal of Hospice \& Palliative Nursing, 17, 66-72. doi:10.1097/ NJH.0000000000000126

Miller, K. I. (2007). Compassionate communication in the workplace: Exploring processes of noticing, connecting, and responding. Journal of Applied Communication Research, 35, 223-245. doi:10.1080/ 00909880701434208

Mooney, C., Fetter, K., Gross, B. W., Rinehart, C., Lynch, C., \& Rogers, F. B. (2017). A preliminary analysis of compassion satisfaction and compassion fatigue with considerations for nursing unit specialization and demographic factors. Journal of Trauma Nursing, 24(3), 158-163. doi:10.1097/JTN.0000000000000284

Nancarrow, S. A., Booth, A., Ariss, S., Smith, T., Enderby, P., \& Roots, A. (2013). Ten principles of good interdisciplinary team work. Human Resources for Health, 11, 11-19. doi:10.1186/1478-4491-11-19

National Sleep Foundation. (2015, February 2). National sleep foundation recommends new sleep times [Press release]. Retrieved from https://www.sleepfoundation.org/pressrelease/national-sleep-foundation-recommends-new-sleep-times

O'Connor, N. (2018, January 19). Consults, consults, and more consults: Strategies for managing inpatient demand in excess of staffing [web log comment]. Retrieved from https:// www.capc.org/blog/palliative-pulse-palliative-pulse-january-2018-strategies-manag ing-inpatient-demand/

Omilion-Hodges, L. M., \& Ackerman, C. D. (2018). From the technical know-how to the free flow of ideas: Exploring the effects of leader, peer, and team communication on employee creativity. Communication Quarterly, 66(1), 38-57. doi:10.1080/01463373 .2017 .1325385 
Omilion-Hodges, L. M., \& Swords, N. M. (2016). Communication that heals: Mindful communication practices from palliative care leaders. Health Communication, 31(3), 328-335. doi:10.1080/10410236.2014.953739

Palliative Dork [@PCDorkClub]. Tweets: 5/29/19, 5/14/19, 4/5/19. Retrieved from https:// twitter.com/PCDorkClub

Sanchez-Reilly, S., Morrison, L. J., Carey, E., Bernacki, R., O’Neill, L., Kapo, J., ... deLima Thomas, J. (2013). Caring for oneself to care for others: Physicians and their self-care. The Journal of Supportive Oncology, 11(2), 75-81. Retrieved from https://www.ncbi.nlm .nih.gov/pmc/articles/PMC3974630/

Sans, N., Galiana, L., Oliver, A., Pascual, A., Sinclair, S., \& Benito, E. (2015). Palliative care professionals' inner life: Exploring the relationships among awareness, self-care, and compassion satisfaction and fatigue, burnout, and coping with death. Journal of Pain and Symptom Management, 50, 200-207. doi:10.1016/j.jpainsymman.2015.02.013

Shanafelt, T. D., West, C. P., Sloan, J. A., Novotny, P. J., Poland, G. A., Menaker, R., ... Drybye, L. N. (2009). Career fit and burnout among academic faculty. Archives of Internal Medicine 169(10), 990-995. doi:10.1001/archinternmed.2009.70

Shanafelt, T. D., West, C. P., Zhao, X., Novotny, P., Kolars, J., Habermann, T., \& Sloan, J. (2005). Relationship between increased personal well-being and enhanced empathy among. Journal of General Internal Medicine, 20(7), 559-564. doi:10.1007/s11606-005 $-0102-8$

Sims, S., Hewitt, G., \& Harris, R. (2015). Evidence of collaboration, pooling of resources, learning and role blurring in interprofessional healthcare teams: A realist synthesis. Journal of Interprofessional Care, 29(1), 20-25. doi:10.3109/13561820.2014.939745

Sorenson, C., Bolick, B., Wright, K., \& Hamilton, R. (2016). Understanding compassion fatigue in healthcare providers: A review of current literature. Journal of Nursing Scholarship, 48(5), 456-465. doi:10.1111/jnu.12229

Spilman, J. (2010, November 1). Cumulative grief in healthcare professionals [web log comment]. Retrieved from https://caregiverwellness.blogspot.com/2010/11/cumulative -grief-in-healthcare.html

Swetz, K. M., Harrington, S. E., Matsuyama, R. K., Shanafelt, T. D., \& Lyckholm, L. J. (2009). Strategies for avoiding burnout in hospice and palliative medicine: Peer advice for physicians on achieving longevity and fulfillment. Journal of Palliative Medicine, 12(9), 773-777. doi:10.1089/jpm.2009.0050

Vedel, I., Ghadi, V., Lapointe, L., Routelous, C., Aegerter, P., \& Guirimand, F. (2014). Patients', family caregivers', and professionals' perspectives on quality of palliative care: A qualitative study. Palliative Medicine, 28(9), 1128-1138. doi:10.1177/0269216314532154.

West, C. P., Huschka, M. M., Novotny, P. J., Sloan, J. A., Kolars, J. C., Habermann, T. M., \& Shanafelt, T. D. (2006). Association of perceived medical errors with resident distress and empathy: A prospective longitudinal study. The Journal of the American Medical Association, 296(9), 1071-1078. doi:10.1001/jama.296.9.1071 